\section{Original article}

\title{
Herpes zoster and the stage and prognosis of HIV-1 infection
}

\author{
Anna McNulty, Y Li, Ulrike Radtke, J Kaldor, R Rohrsheim, D A Cooper, B Donovan
}

Objectives: To examine the incidence of herpes zoster in HIV-1 infection. To assess the prognostic significance of the occurrence of herpes zoster and progression to AIDS or death.

Design and methods: 146 homosexually active men with known times of HIV-1 seroconversion were identified through the Sydney AIDS Prospective Study and the clinic records of a private medical practice with large caseload of HIV infected homosexual men. Medical records were reviewed for a history of herpes zoster, CD4+ lymphocyte counts, and HIV-1 disease status. Cox's proportional hazards model was used to determine whether herpes zoster predicted progression to AIDS or death.

Results: After a mean follow up of 54 months, 30 men (20\%) had an episode of herpes zoster and three of these men had one recurrence. The overall incidence of herpes zoster was 44.4 episodes per 1000 person years $(95 \%$ CI $30 \cdot 0-63 \cdot 5)$. Herpes zoster was not found to be a marker of deteriorating immune function as measured by CD4+ lymphocyte counts. CD4+ counts did not differ significantly between those with and without zoster at 1 year $\left(551 v 572 \times 10^{6} / 1, \mathrm{p}=0 \cdot 79\right)$, 2 years (451 $v 557, \mathrm{p}=0.11$ ), and 3 years $(424 v 481, \mathrm{p}=0.50)$ following HIV-1 seroconversion. There was no statistically significant difference in progression to AIDS (RR $=1.89,95 \% \mathrm{CI}$ $0 \cdot 80-4 \cdot 46, \mathrm{p}=0.15)$ or death $(\mathrm{RR}=0.90,95 \%$ CI $0.31-2 \cdot 65, \mathrm{p}=0.85)$ from HIV-1 seroconversion in those who did and those who did not develop herpes zoster.

Conclusion: The incidence of herpes zoster was consistent with the findings of other studies. There was no association between the occurrence of herpes zoster and progression of HIV-1 disease.

(Genitourin Med 1997;73:467-470)

Keywords: herpes zoster; HIV infection; homosexual men; prognosis

\section{Introduction}

Herpes zoster is primarily a disease of the elderly, manifesting in the sixth and seventh decades of life. ${ }^{2}$ Herpes zoster is also known to be associated with immunosuppression. ${ }^{3-6}$ Early in the 1980 s it was noted that herpes zoster was more common in people at high risk of developing AIDS. ${ }^{7-12}$ Following the discovery of human immunodeficiency virus type 1(HIV-1), further studies confirmed the association between herpes zoster and HIV-1 infection. ${ }^{13-16}$

The precise relation between herpes zoster

Taylor Square Private Clinic, Darlinghurst, NSW, 2010 Australia A M McNulty

U Radtke

National Centre in HIV Epidemiology and Clinical Research, Darlinghurst, NSW, 2010, Australia

D A Cooper

J M Kaldor

Y Li

Sydney Sexual Health Centre, Sydney

Hospital, Sydney, NSW, 2000, Australia

B J Donovan

R Rohrsheim

Correspondence to: Dr Anna McNulty, National Centre in HIV Epidemiology and Clinical Research, 376 Victoria Street, Darlinghurst, NSW, 2010, Australia.

Accepted for publication 24 July 1997 and the natural history of HIV infection remains unclear. While in some studies herpes zoster has been described as occurring early in the course of HIV disease, ${ }^{13}{ }^{15-18}$ others have found that it correlates with a later stage ${ }^{14} 19$ and two studies found no association between the incidence of herpes zoster and the duration of HIV infection. ${ }^{20} 21$

The prognostic significance of the occurrence of herpes zoster in HIV-1 infection has also been debated. It has been associated with a more rapid progression to AIDS in some studies $^{18} 22$ while others have found no such association. ${ }^{192023}$ One study found that a first episode of herpes zoster that occurs with advanced HIV-1 infection is associated with an improved prognosis. ${ }^{24}$

In a cohort of homosexual men with known dates of seroconversion to HIV-1 we examined the relation between herpes zoster and duration of HIV-1 infection and assessed the prog- nostic significance of the occurrence of herpes zoster for the progression to AIDS and death.

\section{Methods}

STUDY POPULATION

Study subjects were homosexual men with known dates of seroconversion to HIV-1. They were drawn from two sources: the Sydney AIDS Prospective Study (SAPS) and Taylor Square Private Clinic (TSPC), a medical practice providing primary care and sexually transmissible diseases (STD) services in central Sydney. The SAPS was a cohort study of the behavioural, clinical, immunological, and virological factors associated with the incidence, prevalence, and natural history of HIV1 infection in homosexual and bisexual men. Between February 1984 and January 1985, a total 1074 men were enrolled into the SAPS. ${ }^{25}$ All SAPS subjects who seroconverted between 1984 and 1990 , as defined by a positive HIV-1 antibody test following a documented negative HIV-1 antibody test, were eligible for inclusion in the present study.

Estimated time of seroconversion was taken as the midpoint between the negative and first positive HIV antibody tests. From TSPC records, all homosexual or bisexual male patients of the clinic were identified who first attended between 1984 and 1992 and fulfilled the same definition of $\mathrm{HIV}-1$ seroconversion as SAPS subjects. Only subjects who had a minimum of 6 months' follow up from the 
time of the first positive HIV antibody test were analysed.

AIDS was defined according to the 1987 revised definition of the Centers for Disease Control (CDC). ${ }^{26}$ Follow up of each case was until the end of 1992. Lost to follow up was defined as those subjects who had not been seen 1 year after their last visit and were not known to be dead.

\section{DATA COLLECTION}

For each study subject, medical records were reviewed to obtain information on diagnoses of herpes zoster; date of starting antiretroviral therapy with zidovudine, CD4+ and CD8+ lymphocyte percentages and absolute counts within 3 months of 1,2 , and 3 years after seroconversion. Dates of AIDS and death were also recorded if either of these events had occurred. For subjects not reported as having died, the date of last contact was recorded.

Subjects enrolled in the SAPS were asked to undergo 6 monthly assessments which included a self administered questionnaire, physical examination by their medical practitioner, and immunological tests. From 1987, the SAPS questionnaire sought information on the occurrence of herpes zoster. The SAPS questionnaires were reviewed for the current study. Further information on herpes zoster was sought from medical practitioners who had originally recruited SAPS subjects in whom HIV seroconversion was subsequently documented.

\section{LABORATORY TESTS}

Before 1986, sera were screened for antibody to HIV-1 by enzyme linked immunosorbent assay (ELISA) produced by ElectroNucleonics Inc, Columbia USA, or Abbott Laboratories, North Chicago, USA. Reactive samples were retested with the ENI assay incorporating the $\mathrm{H} 9$ exclusionary test, and with an immunofluorescence assay.

From 1986 to 1992 the screening was by ELISA (Genetic Systems, Seattle, USA) and Wellcozyme (Wellcome Laboratories, UK) followed by western blot confirmation (BioRad Laboratories, Hercules, USA).

\section{DATA ANALYSIS}

We calculated the incidence of herpes zoster per 1000 person years for each year, up to 8 years, following HIV-1 seroconversion. ${ }^{27}$ Cox's proportional hazards model ${ }^{28}$ was used to determine whether the occurrence of herpes zoster predicted progression to AIDS or to death, taking account of age at seroconversion; zidovudine use, and CD4+ counts. Herpes zoster was included as a time dependent covariate $^{28}$ taking the value "zero" before the date of herpes zoster onset and "one" from the date of onset until the end of follow up. The effect of zidovudine use was analysed in the same way. Absolute CD4+ counts were compared at 12, 24, and 36 months following HIV-1 seroconversion between those who developed herpes zoster and those who did not, again taking account of age at seroconversion and zidovudine use by multiple regression analysis. All $\mathrm{p}$ values were two tailed and type one error was set at $5 \%$.

\section{Results}

Between the SAPS and the TSPC records, 146 were identified as having undergone HIV1 seroconversion. The mean age at $\mathrm{HIV}-1$ seroconversion of the 146 men in our cohort was 32 years (SD 8 years). Data on the seroconversion interval were available for the SAPS cohort. The median interval between the last negative HIV antibody test and the first positive HIV antibody test was 201 days. One year after their last visit four subjects $(2.7 \%)$ were lost to follow up; $19(13.0 \%)$ at 2 years; $33(22.6 \%)$ at 3 years; $49(33.6 \%)$ at 4 years; $68(46.6 \%)$ at 5 years; $84(57.5 \%)$ at 6 years; and $104(71 \cdot 2 \%)$ at 7 years.

\section{INCIDENCE OF HERPES ZOSTER IN HIV-1} INFECTION

After a mean follow up of 54 months, 30 men $(20 \%)$ had an episode of herpes zoster and three of these men $(10 \%)$ had one recurrence. The overall incidence of herpes zoster was 44.4 episodes per 1000 person years $(95 \%$ CI $30 \cdot 0-63 \cdot 5)$. The incidence in the first year following HIV-1 seroconversion was 13.8 cases per 1000 person years; 51.9 in year $2 ; 91.5$ in year $3 ; 59.8$ in year $4 ; 13.4$ in year $5 ; 17.8$ in year 6 ; and 60.8 in year 7 . The cumulative proportion of men developing herpes zoster in the years following HIV-1 seroconversion calculated by the Kaplan-Meier method is illustrated in figure 1.

\section{HERPES ZOSTER AND THE NATURAL HISTORY} OF HIV-1 INFECTION

Of the 30 patients who developed herpes zoster, seven (23\%) had developed AIDS by the end of the study period and five $(17 \%)$ had died. Within the group who did not develop herpes zoster, 24 (21\%) developed AIDS during the study period and $20(17 \%)$ had died; two of these 20 deaths were before an AIDS diagnosis and in two cases data were not available. Zidovudine use was recorded in 66 $(45 \cdot 2 \%)$ of the cohort.

Herpes zoster was not found to be a marker of deteriorating immune function as indicated

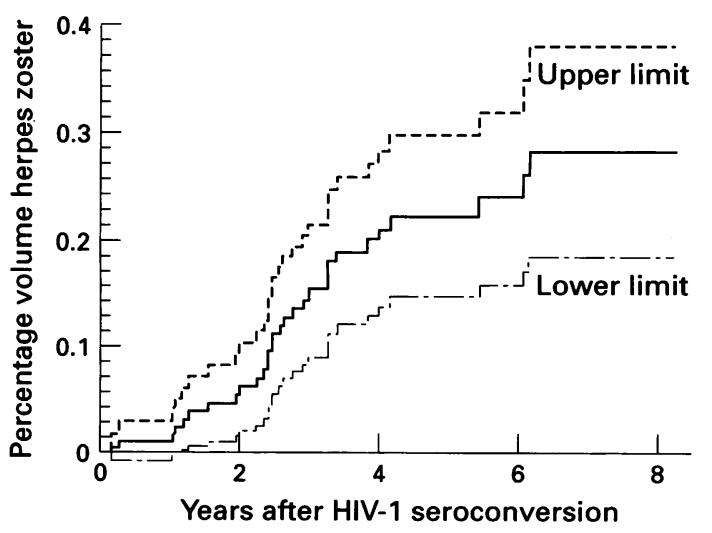

Figure 1 Cumulative proportion of HIV-1 infected men developing herpes zoster with $95 \%$ confidence intervals. 


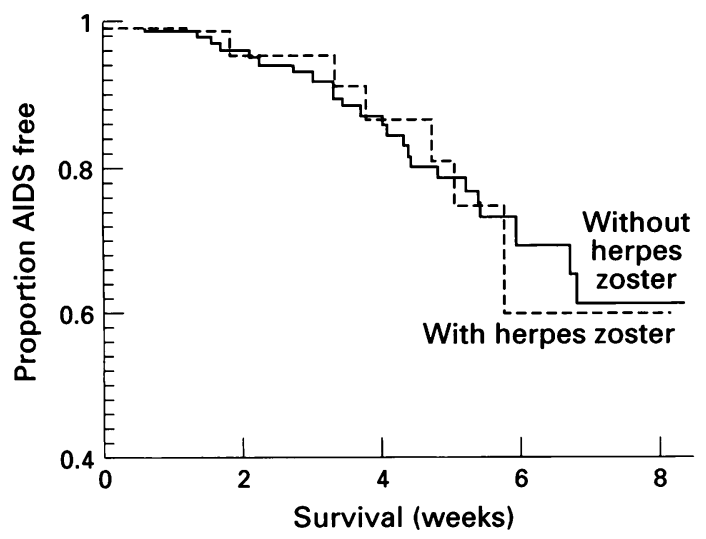

Figure 2 AIDS free survival from $H I V-1$ seroconversion by occurrence of herpes zoster.

by $\mathrm{CD} 4+$ and $\mathrm{CD} 8+$ counts. CD4+ counts did not differ significantly between those with and without zoster at 1 year $(551 v 572, \mathrm{p}=$ 0.79 ), 2 years ( $451 v 557, \mathrm{p}=0.11$ ), and 3 years $(424 v 481, \mathrm{p}=0.50)$ following HIV-1 seroconversion. There was no significant difference in CD8+ counts between those with and without zoster at 1 year (951 v 948, p = $0.98), 2$ years (984 $v 986, \mathrm{p}=0.99$ ), and 3 years $(1052 v 1007, \mathrm{p}=0 \cdot 78)$ following HIV1 seroconversion. CD4+ and CD8+ counts were available for $77(52 \cdot 7 \%)$ of the cohort at 1 year, $84(57 \cdot 5 \%)$ at 2 years, and $72(49 \cdot 3 \%)$ at 3 years.

Progression to AIDS from HIV-1 seroconversion was more rapid in those who developed herpes zoster, but not significantly so $(R R=1 \cdot 89,95 \%$ CI $0 \cdot 80-4 \cdot 46, p=0 \cdot 15)$. The association between herpes zoster and progression from HIV-1 seroconversion to death was weaker, $R R=0.90 \quad(95 \% \quad C I$ $0 \cdot 31-2 \cdot 65, p=0 \cdot 85)$. The AIDS free survival time from HIV-1 seroconversion, in people who did and did not develop herpes zoster, is shown in figure 2.

\section{Discussion}

The $21 \%$ cumulative incidence of herpes zoster after a mean of 54 months of follow up reported in our HIV-1 seroincident group is comparable to the rate of $21 \%$ after 50 months' follow up reported in a United States study. ${ }^{24}$ On the other hand, the incidence rate of 44.4 herpes zoster cases per 1000 person years was higher than in a previous study in the United States ${ }^{20}$ which reported an incidence rate of 29.4 and another study in France reported a rate of $34 \cdot 5,{ }^{21}$ but it was lower than a recent report from the Netherlands with a rate of 51.5 cases per 1000 person years. ${ }^{19}$ The $10 \%$ recurrence rate of herpes zoster was similar to that reported by others. ${ }^{15} 2124$

Consistent with other studies, ${ }^{20}{ }^{21}$ this investigation did not find any association between the occurrence of herpes zoster and the stage of HIV-1 infection as measured by CD4+ cell count. However, a recent study ${ }^{19}$ noted that the incidence of herpes zoster increased with decreases in CD4+ cell count and T cell reactivity as measured by $\mathrm{CD} 3$ monoclonal anti- body response and phytohaemagglutinin response. Veenstra et al found that those with CD4+ counts of less than 200 had an incidence of herpes zoster three times that of those with more than $500 \mathrm{CD} 4+$ cells. An explanation for the difference in findings of Veenstra et al s study and our study may be that our study focused on those with early HIV infection whereas herpes zoster may be a condition associated with longer duration of infection. In those with high CD $4+$ counts, measures of $T$ cell reactivity may be a more accurate predictor of risk of developing herpes zoster. Studies that have described herpes zoster as occurring either early ${ }^{13-18}$ or late ${ }^{14}$ in disease, have not been based on subjects with known times of HIV-1 seroconversion, and have relied on clinical symptoms or CD4+ cell counts to estimate the stage of HIV-1 disease.

Occurrence of herpes zoster was not associated with more rapid progression to AIDS or death, again in agreement with three recent studies. ${ }^{192024}$ Veenstra et al s study ${ }^{19}$ found an association with more rapid disease progression and a first episode of herpes zoster however this was not significant after controlling for CD4+ count.

There are a number of limitations to our study. A substantial number of subjects were lost to follow up or had incomplete outcome data. This may have produced a selection bias. It is possible that those with an early clinical manifestation of immune deficiency such as herpes zoster, were more likely to attend for follow up. Other potential sources of bias include the reduced sensitivity of early HIV antibody tests compared with currently available tests. However, all seroconverters identified before 1986 had their sera retested by ELISA to HIV-1. The assumption that HIV seroconversion occurred at the mid point between the last HIV antibody negative test and the first HIV antibody positive test may not be valid. However, $71 \%$ of the seroconverters identified had an interval of less than 2 years between tests.

The lack of association between the degree of immune suppression as determined by CD4+ and CD8+ cell counts and the occurrence of herpes zoster raises the interesting question of the pathophysiological process by which herpes zoster is associated with HIV-1 infection. A decrease in cellular immunity has been thought to be responsible for the reactivation of varicella zoster virus. ${ }^{6} \mathrm{~A}$ recent study of herpes zoster in HIV infection ${ }^{19}$ noted an association with decreasing CD4+ counts and herpes zoster incidence but also noted that a decrease in $T$ cell reactivity was an independent predictor for herpes zoster.

The occurrence of herpes zoster has been used as a clinical end point to evaluate the efficacy of early zidovudine therapy. ${ }^{29}$ Better understanding of the relation between the prognosis of HIV-1 infection and the appearance of herpes zoster could assist in the management of HIV-1 infection. This study was supported by the Commonwealth AIDS
Research Grants Committee. The National Centre in HIV Epidemiology and Clinical Research is supported by the 
Australian National Council on AIDS through the Commonwealth AIDS Research Grants Committee. The authors wish to thank the homosexual men who have participated in the Sydney AIDS Prospective Study and Dr Tim Barnes, Dr Sandy Beveridge, Dr Peter Brooke, Dr Robert Finlayson, Dr Bill Genn, Dr Philip Haynes, Dr Harry Michelmore, Dr Ross Price, Dr Mark Robertson, Dr Brett Tindall (deceased), Ms Jeanette Vizzard, and Dr Clive Wolfe for supplying data for this study. We would also like to thank Dr Neil Bodsworth for his assistance with establishing the Dr Neil
study.

1 Hope-Simpson RE. The nature of herpes zoster: a longterm study and a new hypothesis. Proc $R$ Soc Med 1965; 58:9-20.

2 Ragozzino MW, Melton 111 LJ, Kurland LT, Chu CP, Perry HO. Population-based study of herpes zoster and its sequelae. Medicine 1982;61:310-6.

3 Balfour $\mathrm{HH}$. Varicella zoster virus infections in immunocomprised hosts. A review of the natural history and management. Am $\mathcal{F}$ Med 1988;85(suppl 2A):68-72.

4 Dolin R, Reichman RC, Mazur MH, Whitley RJ. Herpes zoster-varicella infections in immunosuppressed patients. Ann Intern Med 1978;89:375-88.

5 Ljungman P, Lonnqvist B, Gahrton G, Ringden $O$, Sundqvist V, Wahren B. Clinical and subclinical reactiSundqvist V, Wahren B. Clinical and subclinical reacti-
vations of varicella-zoster virus in immunocompromised patients. F Infect Dis 1986;153:840-7.

6 Weller TH. Varicella and herpes zoster. Changing concepts of the natural history, control and importance of a notso-benign virus. N Engl f Med 1983;309:1434-40

7 Masur H, Michelis MA, Greene JB, Onorato I, Stouwe RA, Holzman RS, et al. An outbreak of communityacquired Pneumocystis carinii pneumonia. $N$ Engl $₹ \mathrm{Med}$ 1981;305:1431-8.

8 Sandor E, Croxson TS, Millman A, Mildvan D. Herpes zoster ophthalmicus in patients at risk for AIDS. $N$ Engl $F$ Med 1984;310:1119.

9 Rowland Payne CME, Farthing C, Byrom N, Staughton RCD. Shingles in seven homosexuals. Lancet 1984;1: 103-4.

10 Cone LA, Schiffman MA. Herpes zoster and the acquired immunodeficiency syndrome. Ann Intern Med 1984;100: 462.

11 Pinching AJ, McManus TJ, Jeffries DJ, Moshtael O, Donaghy H, Parkin JM, et al. Studies of cellular immunity in male homosexuals in London. Lancet 1983;2: 126-30.

12 Daly HM, Scott GL. Fatal AIDS in a haemophiliac in the UK. Lancet 1983;2:1190.

13 Verroust F, Lemay D, Laurian Y. High frequency of herpes zoster in young hemophiliacs. $N$ Engl f Med 1987;316: 166.

14 Melbye M, Biggar RJ, Ebbesen P, Neuland C, Goedert J, Faber V, et al. Long-term seropositivity for human Tlymphotrophic virus type 111 in homosexual men without the acquired immunodeficiency syndrome: development of immunologic and clinical abnormalities. Ann Intern Med 1986;104:496-500.

15 Friedman-Kien AE, Lafleur MPH, Gendler E, Hennessey NP, Montagna R, Halbert S, et al. Herpes zoster: a possible early clinical sign of acquired immunodeficiency syndrome in high risk individuals. Am Acad Derm 1986 14:1023-8.

16 Colebunders R, Mann JM, Francis H, Bila K, Izaley I, Ilwaya $M$, et al. Herpes zoster in African patients: a clinical predictor of human immunodeficiency virus infection. f Infect Dis 1988;157:314-8.

17 Van de Perre P, Bakkers E, Batungwanayo J, Kestelyn P, Lepage P, Nzaramba D, et al. Herpes zoster in African patients: an early manifestation of HIV infection. Scand $\mathscr{f}$ Infect Dis 1988;20:277-82.

18 Melbye M, Grossman RJ, Goedert JJ, Eyster ME, Biggar RJ. Risk of AIDS after herpes zoster. Lancet 1987;1: 728-31.

19 Veenstra J, Krol A, van Praag RME, Frissen PH, Schellekens PT, Lange JM, et al. Herpes zoster, immunological deterioration and disease progression in HIV-1 infection. AIDS 1995;9:1153-8.

20 Buchbinder SP, Katz MH, Hessol NA, Liu JY, O'Malley PM, Underwood R, et al. Herpes zoster and human immunodeficiency virus infection. $\mathcal{F}$ Infect Dis 1992;166: immunodeficiency virus infectic 1153-6.

21 Rogues AM, Dupon M, Ladner J, Ragnaud JM, Pellegrin JL, Dabis $F$ and Groupe d'Epidemilogie Clinique du SIDA en Aquitaine. Herpes zoster and human immunodeficiency virus infection: a cohort study of 101 coinfected patients. F Infect Dis 1993;168:245

22 van Griensven GJP, de Vroome EMM, de Wolf F, Goudsmit J, Roos M, Coutinho RA. Risk factors for progression of human immunodeficiency virus (HIV) infection among seroconverted and seropositive homosexual men. Am $\mathcal{~}$ Epidemiol 1990;132:203-10.

23 Moss AR, Bacchetti P, Osmond D, Krampf W, Chaisson RE, Stites D, et al. Seropositivity for HIV and the develRE, Stites D, et al. Seropositivity for HIV and the develfollow up of the San Francisco General Hospital cohort. follow up of the San Fran

24 Glesby MJ, Moore RD, Chaisson RE, and the Zidovudine Epidemiology Study Group. Herpes zoster in patien with advanced human immunodeficiency virus infection treated with zidovudine. $\mathcal{F}$ Infect Dis 1993;168:1264-8.

25 Sydney AIDS Study Group. The Sydney AIDS Project. Med f A ust 1984;143:569-73.

26 Centers for Disease Control. Revision of the CDC surveillance case definition for AIDS. MMWR 1987;36:3S-15S

7 Hennekens $\mathrm{CH}$, Buring J. Epidemiology in medicine. Boston: Little Brown, 1987.

28 Cox DR, Oakes D. Analysis of survival data. London: Chapman and Hall, 1984.

29 Cooper DA, Gatell, JM, Kroon S, Clumeck N, Millard J, Goebel F-D, et al. Zidovudine in persons with asymptomatic HIV infection and CD4+ cell counts greater than 400 per cubic millimeter. $N$ Engl $f$ Med 1993;329. 297-303. 